\title{
Relationship between postpartum depression and lactation
}

\section{status at a Japanese perinatal center: A cross-sectional study \\ [version 1; peer review: 1 approved with reservations]}

\author{
Shunji Suzuki (iD)
}

Department of Obstetrics and Gynecology, Japanese Red Cross Katsushika Maternity Hospital, Tateishi, Katsushika-ku, Tokyo, 1240012, Japan

\author{
V1 First published: 04 Nov 2019, 8:1845 \\ https://doi.org/10.12688/f1000research.20704.1 \\ Latest published: 30 Jan 2020, 8:1845 \\ https://doi.org/10.12688/f1000research.20704.2
}

\section{Abstract}

Background: Some studies have demonstrated that breastfeeding can protect mothers from postpartum depression; therefore, we examined the association between postpartum depression and lactation status at one month after delivery at a Japanese perinatal center.

Methods: We reviewed the obstetric records of all (total 809) nulliparous healthy women with vaginal singleton delivery at 37-41 weeks' gestation at our institute between July 2018 and June 2019. A face-to-face interview with the women was conducted on admission for delivery to ask whether or not they hoped to perform exclusive breastfeeding for their babies, and an additional interview was conducted one month after delivery to ask about their feeding methods currently. Maternal mental status was examined based on the scores using the Edinburgh Postnatal Depression Scale (EPDS), and women with EPDS scores of $\geq 9$ points were regarded as 'positive screening'.

Results: 592 women (73.1\%) hoped to perform exclusive breastfeeding for their babies on admission. Of these, at one month, 442 (74.7\%) performed exclusive breastfeeding, while 150 (25.3\%) performed mixed or artificial feeding. The average EPDS scores and the incidence of EPDS scores $\geq 9$ points in the women performing exclusive breastfeeding were $4.3 \pm 3.6$ and $14.3 \%$ (63/442), respectively. They did not differ from those in the women performing mixed or artificial breast feeding [4.2 $\pm 3.7, p=0.60$ and $13.3 \%$ (20/150), $p=0.78]$.

Conclusion: Development of postpartum depression does not seem to be associated with incomplete breastfeeding at our hospital, and therefore there are other risk factors indicated in the development of postpartum depression.

Open Peer Review
Approval Status
version 2
(revision)
30 Jan 2020
version 1
04 Nov 2019
1. Hir...............................................................
Japan
2. Felix Emeka Anyiam
Harcourt, Port Harcourt, Nigeria
Any reports and responses or comments on the
article can be found at the end of the article.


Keywords

postpartum depression, lactation status, exclusive breastfeeding, the Edinburgh Postnatal Depression Scale, Japan

Corresponding author: Shunji Suzuki (czg83542@mopera.ne.jp)

Author roles: Suzuki S: Conceptualization, Data Curation, Formal Analysis, Funding Acquisition, Investigation, Methodology, Project Administration, Resources, Software, Supervision, Validation, Visualization, Writing - Original Draft Preparation, Writing - Review \& Editing

Competing interests: No competing interests were disclosed.

Grant information: The author(s) declared that no grants were involved in supporting this work.

Copyright: $\odot 2019$ Suzuki S. This is an open access article distributed under the terms of the Creative Commons Attribution License, which permits unrestricted use, distribution, and reproduction in any medium, provided the original work is properly cited.

How to cite this article: Suzuki S. Relationship between postpartum depression and lactation status at a Japanese perinatal center: A cross-sectional study [version 1; peer review: 1 approved with reservations] F1000Research 2019, 8:1845 https://doi.org/10.12688/f1000research.20704.1

First published: 04 Nov 2019, 8:1845 https://doi.org/10.12688/f1000research.20704.1 


\section{Introduction}

Exclusive breastfeeding for the first 6 months of life has been recommended because of important health, medical, social, and developmental benefits to both mothers and babies ${ }^{1}$. Postpartum depression has been recognized as the leading medical complication among new mothers ${ }^{2,3}$. To date, some risk factors for postpartum depression, such as personal and family factors, socioeconomic status, support from other family members and personal plans for furthering careers, have been examined ${ }^{4-8}$. Some studies have demonstrated that breastfeeding can protect mothers from postpartum depression and are starting to clarify which biological and psychological processes may explain this protection ${ }^{9-11}$. In addition, a short duration of breastfeeding has been reported to be associated with the development of postpartum depression ${ }^{11}$.

In Japan, the breastfeeding rate at Japan's baby-friendly hospitals (BFHs) at one month of age has been reported to be more than $75 \%^{12}$; however, inconsistent knowledge of breastfeeding benefits and inappropriate hospital practices has been reported to be associated with the increased use of infant formula and reduced breastfeeding duration, although the national breastfeeding rates had been higher than other countries of similar health status $^{13}$. Unfortunately, only $50 \%$ of women who delivered at Japanese Red Cross Katsushika Maternity Hospital, a non-BFH institute, have performed exclusive breastfeeding for their babies at one month after delivery ${ }^{14,15}$. Recently, in Japan, the population of elderly and/or high-risk pregnant women has been increased, and the rate of exclusive breastfeeding may be expected to decrease $e^{4}$. To examine the necessity of breastfeeding promotion in relation to maternal mental status, we examined the association between lactation status and postpartum depression at one month after delivery in Japanese women.

\section{Methods}

The protocol for this analysis was approved by the Ethics Committee of the Japanese Red Cross Katsushika Maternity Hospital (approval number, K2018001). Written informed consent was obtained from each woman to participate in this study at the first meeting, i.e. before birth.

\section{Participants}

We reviewed the obstetric records of all nulliparous healthy women $(n=809)$ with vaginal singleton delivery at 37-41 weeks' gestation at Japanese Red Cross Katsushika Maternity Hospital between July 2018 and June 2019.

We excluded cases of multiparous women, multiple births, cesarean deliveries, mothers with a habit of smoking and/or drinking, mothers with pregnancy depression, mothers without partners mothers whose babies are low birth weight, and mothers whose babies were admitted to the neonatal intensive care unit (NICU) because they have been already reported to be associated with the prevalence of exclusive breastfeeding and/or postpartum depression ${ }^{4,11,16-18}$.

\section{Data collection}

A face-to-face interview was conducted with the women on admission for delivery to ask them whether or not they hoped to perform exclusive breastfeeding for their babies at the delivery room of the hospital, and an additional interview was conducted one month after delivery to ask about their feeding methods at that time at the outpatient examination room of the hospital during routine check-up appointments.

Maternal mental status was examined, at one month after delivery, based on the scores of the questionnaires of the Edinburgh Postnatal Depression Scale (EPDS) at the same time of the interview. In this study, women with the EPDS scores of $\geq 9$ points were regarded as 'positive screening $=50 \%$ possibility of depression', according to the results of previous observations in Japan by Okano et al. ${ }^{19,20}$.

\section{Data analysis}

Data are presented as the mean \pm SD or number (\%). SPSS Statistics software version 20 (IBM Csorp., Armonk, NY, USA) was used for statistical analyses. For statistical analysis, the $X^{2}$ test for categorical variables and Student's $t$-test for continuous variables were used. Differences with $p<0.05$ were considered significant.

\section{Results}

On admission, 592 women (73.1\%) hoped to perform exclusive breastfeeding for their babies and who met the conditions to be considered in the current study. Of these, $442(74.7 \%)$ performed exclusive breastfeeding at one month, while 150 $(25.3 \%)$ performed mixed or artificial feeding (mixed feeding: 296, artificial feeding: 24). There were no significant differences in maternal age between the two groups (exclusive breastfeeding: $32.4 \pm 6.1$ years; mixed or artificially feeding: $32.8 \pm 6.4$ years; $p=0.11$ ).

The average EPDS scores and the incidence of EPDS scores of $\geq 9$ points in the women performing exclusive breastfeeding were $4.3 \pm 3.6$ and $14.3 \%$ (63/442), respectively. These did not differ from those in the women performing mixed or artificial feeding [4.2 $\pm 3.7, p=0.60$ and $13.3 \%(20 / 150), p=0.78]$. In addition, the average EPDS score and the incidence of EPDS scores of $\geq 9$ points in the women performing exclusive artificial feeding was $4.0 \pm 3.2$ and $8.3 \%$ (2/24), respectively.

\section{Discussion}

Although the rate of exclusive breastfeeding may be low in our institute, it did not seem to be related to the development of postpartum depression. The current results seemed to be contrary to those in some previous studies indicating that breastfeeding can protect mothers from postpartum depression ${ }^{9-11}$.

To date, lower plasma oxytocin levels leading to incomplete breastfeeding have been reported to be associated with the development of postpartum depression. In a recent study by Lara-Cinisomo et $a l .{ }^{10}$, for example, lower levels of plasma oxytocin were observed in women who had stopped breastfeeding and had postpartum depression by two months postpartum. The influence of synthetic oxytocin on a new mother's well-being has been also reported previously ${ }^{10,21,22}$. Oxytocin is released across the breastfeeding cycle, and oxytocin release has observed to exhibit a temporary anxiolytic-like calming effect on postpartum maternal mood disturbances ${ }^{21}$. Therefore, oxytocin is believed to mediate a calming effect on postpartum mood in primiparous mothers with breastfeeding. 
However, in this study, exclusive breastfeeding did not contribute to the prevention of postpartum depression significantly. The mental status of mothers considered to have low levels of oxytocin associate with incomplete breastfeeding seemed to be stable. Therefore, in social environments and/or clinical characteristics of pregnant Japanese women, there may be some serious risk factors for postpartum depression other than the status of breastfeeding, such as personal and family factors, socioeconomic status, support from other family members and personal plans for furthering careers ${ }^{4-8}$. For example, in our recent Japanese study that asked mothers' biggest worry at two weeks after delivery, only $10 \%$ reported anxiety about breastfeeding ${ }^{8}$. Although we believe that Japan is not a poor country, recently there are some morbid pregnant women who have been reduced to poverty ${ }^{23}$.

We understand the small sample of the current study is a serious limitations. A study in women who gave birth at BFHs may have totally different results than the current results. In addition, although the EPDS has been the most widely used screening tool for postpartum depression in maternity and child services in various countries throughout the world, a EPDS high score does not mean the presence of postpartum depression ${ }^{19,20,24,25}$.
In conclusion, development of postpartum depression does not seem to be associated with incomplete breastfeeding in Japanese women at our institute. Consequently, there must be other risk factors associated with the development of postpartum depression. A further larger study is needed to clarify these factors.

\section{Data availability}

Underlying data

Figshare: Breastfeeding and EPDS, https://doi.org/10.6084/ m9.figshare.9925070.v1 $1^{26}$

This project contains the following underlying data:

- Dataset 1. Raw data for maternal age, breastfeeding methods and EPDS score recorded from 592 women who hoped to perform exclusive breastfeeding for their babies.

Data are available under the terms of the Creative Commons Zero "No rights reserved" data waiver (CC0 1.0 Public domain dedication).

Acknowledgements

The author wishes to thank all patients for their collaboration.
1. Kramer MS, Kakuma R: Optimal duration of exclusive breastfeeding. Cochrane Database Syst Rev 2002: 1(8): CD003517. PubMed Abstract | Publisher Full Text

2. Yeaton-Massey A, Herrero T: Recognizing maternal mental health disorders: beyond postpartum depression. Curr Opin Obstet Gynecol. 2019; 31(2): 116-119. PubMed Abstract | Publisher Full Text

3. Pearlstein T, Howard M, Salisbury A, et al.: Postpartum depression. Am J Obstet Gynecol. 2009; 200(4): 357-364.

PubMed Abstract | Publisher Full Text | Free Full Text

4. Takeda S, Takeda J, Murakami K, et al.: Annual Report of the Perinatology Committee, Japan Society of Obstetrics and Gynecology, 2015: Proposal of urgent measures to reduce maternal deaths. J Obstet Gynaecol Res. 2017; 43(1): 5-7.

PubMed Abstract | Publisher Full Text

5. Honjo K, Kimura T, Baba S, et al:: Association between family members and risk of postpartum depression in Japan: Does "who they live with" matter? -The Japan environment and Children's study. Soc Sci Med. 2018; 217: 65-72. PubMed Abstract | Publisher Full Text

6. Muchanga SMJ, Yasumitsu-Lovell K, Eitoku M, et al.: Preconception gynecological risk factors of postpartum depression among Japanese women: The Japan Environment and Children's Study (JECS). J Affect Disord. 2017; 217: 34-41.

PubMed Abstract | Publisher Full Text

7. Iwata H, Mori E, Tsuchiya M, et al:: Predictors of depressive symptoms in older Japanese primiparas at 1 month post-partum: A risk-stratified analysis. Jpn J Nurs Sci. 2016; 13(1): 147-155

PubMed Abstract | Publisher Full Text

8. Suzuki S: Mother's biggest worry at 2 weeks after delivery (in Japanese). Clin Gynecol Obstet (Tokyo). 2017; 71(11): 1107-1111

9. Figueiredo B, Dias CC, Brandão $\mathrm{S}$, et al.: Breastfeeding and postpartum depression: state of the art review. J Pediatr (Rio J). 2013; 89(4): 332-338. PubMed Abstract | Publisher Full Text

10. Lara-Cinisomo S, McKenney K, Di Florio A, et al.: Associations Between Postpartum Depression, Breastfeeding, and Oxytocin Levels in Latina Mothers. Breastfeed Med. 2017; 12(7): 436-442. PubMed Abstract | Publisher Full Text | Free Full Text

11. Dias CC, Figueiredo B: Breastfeeding and depression: a systematic review of the literature. J Affect Disord. 2015; 171: 142-154. PubMed Abstract | Publisher Full Text
12. Yoda T, Takahashi $\mathrm{K}$, Yamauchi $\mathrm{Y}$ : Japanese trends in breastfeeding rate in baby-friendly hospitals between 2007 and 2010: a retrospective hospital-based surveillance study. BMC Pregnancy Childbirth. 2013; 13: 207. PubMed Abstract | Publisher Full Text | Free Full Text

13. Inoue $\mathrm{M}$, Binns $\mathrm{CW}$, Otsuka $\mathrm{K}$, et al:: Infant feeding practices and breastfeeding duration in Japan: A review. Int Breastfeed J. 2012; 7(1): 15. PubMed Abstract | Publisher Full Text | Free Full Text

14. Suzuki S, Hirohata S, Uriu K, et al.: Cesarean delivery as a factor promoting exclusive breastfeeding in Japan. J Matern Fetal Neonatal Med. 2013; 26(17): 1762-1763.

PublMed Abstract | Publisher Full Text

15. Suzuki S: Maternal age and breastfeeding at 1 month after delivery at a Japanese hospital. Breastfeed Med. 2014; 9(2): 101-102. PubMed Abstract | Publisher Full Text

16. Kaneko A, Kaneita Y, Yokoyama E, et al:: Factors associated with exclusive breast-feeding in Japan: for activities to support child-rearing with breastfeeding. J Epidemiol. 2006; 16(2): 57-63. PubMed Abstract | Publisher Full Text

17. Rowe-Murray HJ, Fisher JR: Operative intervention in delivery is associated with compromised early mother-infant interaction. BJOG. 2001; 108(10): 1068-1075. PubMed Abstract | Publisher Full Text

18. Pilch D: [The influence of birth modus on the emotional state of the mother, bonding, and the newborn's neurobehavioural state]. Pomeranian J Life Sci. 2015; 61(3): 249-256.

PubMed Abstract

19. Okano T, Nomura J, Kumar R, et al:: An epidemiological and clinical investigation of postpartum psychiatric illness in Japanese mothers. $J$ Affect Disord. 1998; 48(2-3): 233-240.

PubMed Abstract | Publisher Full Text

20. Okano T: [Perinatal depression--recent topics]. Nihon Rinsho. 2007; 65(9): 1689-1693. PubMed Abstract

21. Niwayama R, Nishitani S, Takamura T, et al.: Oxytocin Mediates a Calming Effect on Postpartum Mood in Primiparous Mothers. Breastfeed Med. 2017; 12 103-109.

PubMed Abstract | Publisher Full Text

22. Gu V, Feeley N, Gold I, et al.: Intrapartum Synthetic Oxytocin and Its Effects on Maternal Well-Being at 2 Months Postpartum. Birth. 2016; 43(1): 28-35. PubMed Abstract | Publisher Full Text 
23. Suzuki S: Economic problems and mental disorders in Japanese pregnant women. J Clin Med Res. 2015; 7(5): 367 PubMed Abstract | Publisher Full Text | Free Full Text

24. Cox JL, Murray D, Chapman G: A controlled study of the onset, duration and prevalence of postnatal depression. Br J Psychiatry. 1993; 163: 27-31. PubMed Abstract | Publisher Full Text
25. Cox JL, Holden J, Henshaw C: Perinatal Mental Health; The Edinburgh Postnatal Depression Scale (EPDS) Manual 2nd Edition. Glasgow, UK. RCPsych Publications (Royal College of Psychiatrists), 2014. Reference Source

26. Suzuki S: breastfeeding and EPDS. figshare. Dataset. 2019. http://www.doi.org/10.6084/m9.figshare.9925070.v' 


\section{Open Peer Review}

\section{Current Peer Review Status: ?}

\section{Version 1}

Reviewer Report 24 January 2020

https://doi.org/10.5256/f1000research.22771.r58361

(C) 2020 Iwata $\mathbf{H}$. This is an open access peer review report distributed under the terms of the Creative Commons Attribution License, which permits unrestricted use, distribution, and reproduction in any medium, provided the original work is properly cited.

\section{Hiroko Iwata}

Graduate School of Nursing, Chiba University, Chiba, Japan

Methods:

How did the author control confounding factors? Postpartum depression is reported to have associations with multiple factors, as the author stated in "Introduction". The author performed univariate analysis (i.e., $\chi_{2}$ test and Student's t-test), not multivariate analysis. If so, results should be interpreted carefully, or some statement as a study limitation is recommended.

Results:

- It is noteworthy and interesting that we could observe a trend of higher score of EPDS and more women with EPDS score of $\geq 9$ among exclusive breastfeeding group of women, though the results were non-significant. How did the author interpret those results? Discussion:

The first sentence "Although the rate of exclusive breastfeeding may be low in our institute..." does not make sense for readers. The author should contextualize its meaning within the Japanese culture.

Is the work clearly and accurately presented and does it cite the current literature? Partly

Is the study design appropriate and is the work technically sound? Partly

Are sufficient details of methods and analysis provided to allow replication by others? Yes

If applicable, is the statistical analysis and its interpretation appropriate? Partly

Are all the source data underlying the results available to ensure full reproducibility? 
Yes

Are the conclusions drawn adequately supported by the results?

Yes

Competing Interests: No competing interests were disclosed.

Reviewer Expertise: postpartum depression, maternity nursing, midwifery, childrearing support for older primiparous mothers

I confirm that I have read this submission and believe that I have an appropriate level of expertise to confirm that it is of an acceptable scientific standard, however I have significant reservations, as outlined above.

\section{Author Response 27 Jan 2020}

Shunji Suzuki, Japanese Red Cross Katsushika Maternity Hospital, Tateishi, Katsushika-ku, Japan

Response to the reviewer,

Many thanks for your careful reading of the manuscript. We appreciate your comments very much. Thank you very much for your suggestions. Based on the queries, we have re-written the many parts of the manuscript.

We have added 'to control confounding factors' in the Methods. In addition, we have added a limitation concerning the confounding factors.

We have arranged the first paragraph of the Discussion as suggested.

Thank you very much for considering our paper, again.

Sincerely yours,

Shunji Suzuki, MD

Department of Obstetrics and Gynecology, Japanese Red Cross Katsushika Maternity Hospital

5-11-12-2 Tateishi, Katsushika-ku, Tokyo 124-0012 Japan

Tel: +81-3-3693-5211

Fax: +81-3-3694-8725

e-mail: czg83542@mopera.ne.jp

Competing Interests: None. 
The benefits of publishing with F1000Research:

- Your article is published within days, with no editorial bias

- You can publish traditional articles, null/negative results, case reports, data notes and more

- The peer review process is transparent and collaborative

- Your article is indexed in PubMed after passing peer review

- Dedicated customer support at every stage

For pre-submission enquiries, contact research@f1000.com 